\section{Onwards and upwards from London 2012}

\author{
Eleanor J Tillett
}

Welcome to British Association of Sport and Exercise Medicine's (BASEM's) issue of the BJSM. As I write this I am reflecting on the ultimate summer of sport as we welcomed the world to Great Britain for the Olympic and Paralympic Games. Hopefully the world had as good time visiting as we did hosting. Many BASEM members and BJSM readers helped provide medical services, along with family and friends who also volunteered in countless ways. I have heard nothing but positive feedback from all those volunteers with phrases such as 'once in a lifetime' and 'incredible atmosphere' frequently being heard. Of course, that TeamGB and ParaGB had fairly good days at the office, probably helped just a little. According to Nevill's editorial (see page 958) we should not have been surprised that our home advantage kicked in, but I like to think it was a bit more than this. A big thanks to Ian McCurdie who won our competition to provide the cover image with a dynamic London 2012 photo from the BMX competition. Have a look online at the blog to see the runners up; two of our number engaged in some fun, non-medical activity at the Games.

\section{WHAT ABOUT THE LEGACY?}

The general public also seem to have been inspired. Is it just wishful thinking that more people seem to be out and about engaged in sport and exercise and active commuting? Maybe these will be the first Games where we can actually show a

Correspondence to Dr Eleanor J Tillett, British Association of Sport and Exercise Medicine (BASEM), Suite 1C, Hutton Business Centre, Bentley Road, Doncaster DN5 9QP, UK;

ejtillett@doctors.org.uk legacy effect in terms of an increase in physical activity? If we are to tap into this spirit it will take all of us to keep up the momentum and engage our patients whenever we can. Check out Haanstra's meta-analysis on 'Increasing physical activity in healthy adults' (see page 998) for the latest evidence. It is a very positive sign that Prime Minister Cameron appointed Lord Coe to lead the Olympic legacy unit. This will support elite sport and develop business prospects for the UK. We hope that the role will extend to promoting physical activity and sport for health (http://tiny.cc/815qkw). Lord Coe, if you are reading this, see ' 7 investments' (below) as a very helpful roadmap.

\section{INSPIRE A GENERATION}

One of the key themes of London 2012 was to 'inspire a generation' and we have our own generation of aspiring healthcare professionals to inspire as well. While most will not specialise purely in sport and exercise medicine, the importance of anyone involved in healthcare understanding the role of physical activity and how to promote it, is vital. Weiler et al's study of UK medical school curriculae (see page 1024) unfortunately shows that teaching on exercise medicine is still largely lacking. On a positive note, the tremendous '7 investments' paper provides anyone who wants to advocate for physical activity with a compelling fourpage prospectus (http://tiny.cc/k25qkw). This key paper was viewed 1400 times in the Olympic month alone. ${ }^{1}$

\section{BASEM: ONWARDS AND UPWARDS TOO}

As many members will know, it's been a difficult 12 months for our organisation but we are working hard to turn things around. Our recent membership survey provided encouraging feedback and this has given some validation to the current exec's plans as well as providing us with many ideas for the future. An important step will be the next BASEM congress on the 22 and 23 November 2012. We have a new central location at St George's Park and an exciting programme including sessions on, 'lessons from the Olympics' and 'pain and the athlete'. There will also be spilt streams to ensure that those with an interest in sports medicine alongside their main practice and those who specialise in SEM are equally served. We look forward to seeing many of you there and please contact us if you want to take a more active role in BASEM.

\section{WHAT ARE YOU GOING TO DO DIFFERENTLY NEXT WEEK?}

In keeping with the recognition that both BASEM and the BJSM have a broad membership, the selection of articles for this issue is equally broad. When time to dedicate to reading articles becomes ever squeezed, I challenge you to find a least one article from which you can take a nugget of information that will influence your clinical practice next week! Take your pick from anterior cruciate ligament injury (see page 979), hip arthroscopy (see page 1016), neck pain (see page 1004), overreaching (see page 1019) and barriers to physical activity (see page 989), to name but some. For me, it will be Hegedus et al's systematic review of the clinical utility of different shoulder examination tests (see page 964). Enjoy!

\section{Competing interests None.}

Provenance and peer review Commissioned; internally peer reviewed.

Accepted 17 September 2012

Br J Sports Med 2012;46:957.

doi:10.1136/bjsports-2012-091808

\section{REFERENCE}

1. Global Advocacy for Physical Activity (GAPA) the Advocacy Council of the International Society for Physical Activity and Health (ISPAH). Non communicable disease prevention: investments that work for physical activity. $\mathrm{Br} \mathrm{J}$ Sports Med 2012;46:709-12. 